\title{
Integrating factors associated with hypertensive patients' self-management using structural equation modeling: a cross-sectional study in Guangdong, China
}

This article was published in the following Dove Press journal:

Patient Preference and Adherence

\author{
Weiwei Ding' \\ Tong $\mathrm{Li}^{1}$ \\ Qiying $\mathrm{Su}^{2}$ \\ Maohua Yuan² \\ Aihua Lin' \\ 'Department of Epidemiology and \\ Health Statistics, School of Public \\ Health, Sun Yat-sen University, \\ Guangzhou, Guangdong, China; \\ ${ }^{2}$ Department of Chronic Disease \\ Management, Dadong Community \\ Healthcare Center, Guangzhou, \\ Guangdong, China
}

\begin{abstract}
Purpose: Hypertension is considered a major public health issue worldwide because of its high frequency and concomitant risk of cardiovascular disease (CVD). Chronic-disease self-management has been proven to be cost-effective, but influencing factors and pathways remain complex and unclear. The purpose of this study was to integrate factors associated with hypertension self-management to provide a theoretical reference for community hypertension management. Methods: A total of 268 community-dwelling hypertensive patients were enrolled in a crosssectional study conducted from July to September in 2017. A questionnaire on demographicdisease characteristics, disease knowledge, social support, self-efficacy, and self-management was completed by patients. Structural equation modeling was performed to verify multiple factors in self-management based on the self-efficacy theory.

Results: The final model showed a good fit to sample data, ie, younger patients with lower CVD risk, shorter disease course, and less disease knowledge and social support predicted less self-efficacy, less hypertension self-management, and less controlled hypertension. Furthermore, social support was negatively correlated with age, CVD risk, and disease course and positively with disease knowledge.
\end{abstract}

Conclusion: Medication adherence is the lowest dimension in self-management, and self-efficacy is vital to consider in the development of self-management interventions. Selfmanagement education and mutual-help groups may be potential solutions with the power of technology. Younger patients with lower CVD risk and shorter disease course are vulnerable and need more attention.

Keywords: hypertension, self-management, associated factors, structural equation model, China, disease knowledge, social support, self-efficacy

\section{Introduction}

Hypertension is considered a major public health issue worldwide because it is highly prevalent and associated with concomitant risks of cardiovascular disease (CVD). In 2014, hypertension prevalence was $22 \%$ globally, resulting in 9.4 million deaths ${ }^{1}$ and 211.8 million lost disability-adjusted life-years (DALYs). ${ }^{2}$ Seven nationwide sampling surveys conducted in China showed an enormous increase in the prevalence of hypertension - from 5.1\% in 1958 to $23.2 \%$ in $2012^{3}$ - and the country has the most DALYs (45.1 million) of any nation. ${ }^{4}$ However, awareness, treatment, and control rates of hypertension in China $\left(46.9 \%, 40.7 \%\right.$, and $15.3 \%$, respectively) ${ }^{3}$ are still much lower than developed countries $\left(67.0 \%, 55.6 \%\right.$, and $28.4 \%$, respectively). ${ }^{5}$
Correspondence: Aihua Lin Department of Epidemiology and Health Statistics, School of Public Health, Sun Yat-sen University, 74 Zhongshan Second Road, Guangzhou, Guangdong 510080, China Tel +86 I36 60375766

Email linaihua@mail.sysu.edu.cn 
Fortunately, hypertension is preventable, with a $10 \mathrm{mmHg}$ reduction in systolic blood pressure $(\mathrm{BP})$ resulting in a $32 \%$ reduction in stroke risk and 14\% relative reduction in ischemic heart-disease risk. ${ }^{6}$ As such, to better control hypertension and prevent CVD, experts have implemented a number of measures, among which chronic-disease self-management is considered cost-effective.

Chronic-disease self-management refers to a chronic disease patient's “ability to manage symptoms, treatment, physical and psychosocial consequences, and lifestyle changes". ${ }^{7}$ Patients with chronic disease are their own principal caregivers. Self-management, with five core skills - problem solving, decision making, resource utilization, forming a patient-health care provider partnership, and taking action - has become the cornerstone of hypertension care and proved significantly to improve health-related behavior and health status and reduce health care utilization. ${ }^{8}$ However, factors that affect self-management are complex. A comprehensive understanding of multiple factors in selfmanagement has important implications for the design of self-management interventions and the well-being of hypertensive individuals.

Self-efficacy theory, defined as the belief that one can succeed in accomplishing a specific task in a specific context, ${ }^{9}$ has been commonly applied in understanding selfmanagement. Interventions targeting the four ingredients performance accomplishments, vicarious experience, verbal persuasion, and physiological states - would enhance selfefficacy and then improve self-management behaviors. The Stanford Chronic Disease Self-Management Program has shown better self-management and health status through interventions based on self-efficacy theory. ${ }^{10}$ Cross-sectional studies have also confirmed the strong association between self-efficacy and adherence to self-care activities. ${ }^{11}$

Disease knowledge and social support seem to be mediators in self-management. Disease knowledge may help patients to understand health problems and therapies better, which would lead to beneficial changes in health behavior ${ }^{12}$ and is essential in grasping self-efficacy skills. Social support refers to companionship, informational, esteem, and instrumental resources provided by a social network consisting of family members and friends. ${ }^{13}$ Preliminary studies showed that social support has the potential to influence self-management behavior significantly, either directly or indirectly, through self-efficacy. ${ }^{14,15}$ However, inappropriate and well-intentioned advice from friends and family members may have unintentional negative influences on selfmanagement behavior. ${ }^{16}$ Evidence remains inconsistent for relationships among disease knowledge or social support and self-management behavior.

Apart from these factors, demographic and disease characteristics also have an influence on self-management. It is universally acknowledged that better self-management can be found among patients with higher education, higher personal income, medical insurance, and longer disease course. ${ }^{17}$ However, in regard to age, sex, race/ethnicity, marital status, employment, and hypertension stage, relationships with selfmanagement remain heterogeneous. ${ }^{11,18}$

Guangzhou - the most populous city in southern Chinahas undergone rapid economic growth and massive change in lifestyle among its residents, accompanied by an increase of hypertension prevalence: from $14.6 \%$ in 2004 to $18.8 \%$ in 2013. ${ }^{19}$ However, there have been few systematic studies in Guangzhou, and rates of awareness, treatment, and control (31.6\%, 28.8\%, $12.6 \%$, respectively) are relatively low compared with national levels. ${ }^{20}$ The high prevalence of hypertension and limited BP control indicates that current interventions are not functioning efficiently. Hidden factors have not been discovered, and exact pathways among identified factors remain unclear.

Consequently, we formulated three hypotheses in the present study. First, self-efficacy would be positively related to self-management. Second, patients' disease knowledge and social support would be positively related to selfmanagement through self-efficacy. Third, demographic and disease characteristics would be mediators in the relationship between self-efficacy and self-management. A structural equation model (SEM) considering factor analysis and linear regression model simultaneously when examining complex associations ${ }^{21}$ was utilized to explore the hypothesized relationships among the constructs.

The purpose of the present study was to explore a coherent model of self-management among community-dwelling hypertensive patients in Guangzhou based on the self-efficacy theory using the SEM. The findings of this study could be of great help for health care professionals in recognizing strong predictors and applying effective strategies in following community hypertension management and paying more attention to vulnerable patients. Other, older urban areas relatively developed economically can use this as a reference.

\section{Methods}

\section{Setting and participants}

A cross-sectional study was undertaken by exploring baseline data from a clustered randomized controlled trial conducted in a randomly selected community health care center in 
Guangzhou, China. The convenient sampling method was applied to recruit participants from residents coming to the center for clinical visits. Inclusion criteria were individuals who had lived in the community for at least 6 months, aged 45-70 years old, with a definite diagnosis of primary hypertension, and taking or had ever taken antihypertensive drugs. Exclusion criteria were individuals with severe cognitive or communication disorder, severe clinical complications requiring hospitalization, and were participating or had participated in other similar programs within the last 6 months. The sample size calculated in the clustered randomized controlled trial was 232 , with $90 \%$ power and $30 \%$ estimated loss rate. The minimum sample size for the SEM should be no less than $200 .^{22}$

The study was conducted in accordance with the Declaration of Helsinki, and the protocol was approved by the ethics committee of the School of Public Health, Sun Yatsen University (2017008). This study was funded by the Guangzhou Science and Technology Program key projects grant number (201707010077). All subjects gave written informed consent for inclusion before they participated.

\section{Measurements}

Two data-gathering methods were used: self-completed questionnaire and physical measurement. The questionnaire included demographics (sex, age, education, marital status, employment, per capita disposable income, and medical insurance), disease characteristics (body-mass index, disease course, clinical complications, family history, hypertension stage, and CVD risk), and patient medication adherence, disease knowledge, social support, self-efficacy, and self-management. BP was measured on site strictly in accordance with the 2010 Chinese guidelines for the management of hypertension ${ }^{23}$ using calibrated electronic sphygmomanometry (HEM-8713; Omron Corporation, Kyoto, Japan). Participants were first asked to take a 5-minute rest and then measured three times with at least 1 minute's rest between every two measurements. Ultimate BP was the average of the last two measurements and classified into stages $1-3$, as shown in Table 1 . Controlled hypertension was regarded as average $\mathrm{BP} \leq 140 / 90 \mathrm{mmHg}$.

\section{Demographic-disease characteristics}

There were three variables included: age, disease course, and CVD risk. Age and disease course were continuous variables, and CVD risk was an ordinal categorical variable (1=low, $2=$ median, and $3=$ high). The definition of CVD risk was as per the 2010 guidelines, as shown in Table 1.

\section{Disease knowledge}

A 28-item disease-knowledge questionnaire was designed based on the 2010 guidelines and Chinese guidelines for patient education on hypertension. ${ }^{24}$ The questionnaire comprised five dimensions: diagnostic criteria (one question), risk factors (nine questions), clinical manifestations (six questions), adverse outcomes (four questions) and self-management strategies (eight questions). Cronbach's $\alpha$ coefficient was 0.603 , indicating the questionnaire was acceptable. The summary score of correct items reflected the patient's knowledge of hypertension.

\section{Social support}

Social support was measured using the Social Support Rating Scale. This ten-item scale includes subjective support (emotional support provided by relatives or friends), objective support (connection with others or participation in social groups and networks), and use of social support. ${ }^{25}$ Scale scores ranged from 12 to 65 , with higher scores indicating greater social support. The instrument had internal consistency of $\alpha=0.89-0.94$ and has shown good reliability in Chinese populations.

\section{Hypertension self-efficacy}

The Hypertension Self-Efficacy Scale was translated from an authorized American scale by professionals and developed

Table I Classification of hypertension stage and CVD risk

\begin{tabular}{l|l|l|l}
\hline $\begin{array}{l}\text { Blood pressure and } \\
\text { risk factors }\end{array}$ & $\begin{array}{l}\text { SBP I40-I59 and/or } \\
\text { DBP 90-99 }\end{array}$ & $\begin{array}{l}\text { SBP I60-I79 and/or } \\
\text { DBP I00-I09 }\end{array}$ & $\begin{array}{l}\text { SBP } \geq \text { I80 and/or } \\
\text { DBP } \geq I \text { I0 }\end{array}$ \\
\hline $\begin{array}{l}\text { Hypertension stage } \\
\text { No risk factors }\end{array}$ & Stage I & Stage 2 \\
One to two risk factors & Low & Moderate & High \\
$\begin{array}{l}\text { Three or more risk factors } \\
\text { or clinical complications }\end{array}$ & Moderate & Moderate & High \\
\hline
\end{tabular}

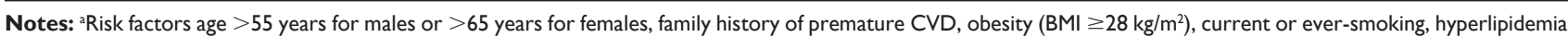

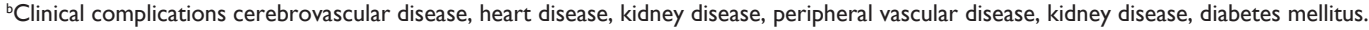

Abbreviations: BMI, body-mass index; CVD, cardiovascular disease; DBP, diastolic blood pressure; SBP, systolic blood pressure. 
to be suitable for Chinese. ${ }^{26}$ This 15 -item scale consists of four subscales: daily life (four questions), health behavior (six questions), medication (three questions), and selfmanagement (two questions). For each of the questions, patients chose the score that corresponded to their confidence in doing certain activities at the present time. Items were scored on a 5-point Likert scale, with higher score indicating better self-efficacy for managing hypertension. The questionnaire proved to have good construct validity (explaining $79.77 \%$ of variance), content validity ( $r=0.916$ ), internal consistency (Cronbach's $\alpha=0.852$ ), and test-retest reliability ( $r=0.869)$, indicating acceptability and feasibility in measuring hypertension self-efficacy, especially among elderly community-dwelling hypertensive patients in Guangzhou.

\section{Medication adherence}

Adherence was measured using the four-item self-reported Morisky-Green-Levine (MGL) measure, ${ }^{27}$ which had been translated into Chinese and validated with a Cronbach's $\alpha$-coefficient of 0.749 in a previous study. ${ }^{28}$ The four items on the MGL are: Do you ever forget to take medications?; Are you ever careless in taking your medications?; Do you ever miss taking your medications when you are feeling better?; and Do you ever miss taking any of your medications because you are feeling sick? Each item had a yes/no response option. One point was assigned to each "no" response, and points were summed, with a higher score indicating better adherence.

\section{Hypertension self-management}

The Hypertension Patients Self-Management Behavior Rating Scale was applied to measure hypertension selfmanagement. ${ }^{29}$ This 33-item scale consists of six parts: medication adherence (four questions), condition monitoring (four questions), diet management (ten questions), sport management (three questions), work management (five questions), and emotion management (seven questions). A 5-point Likert scale from "always" to "never" was utilized for all items. Responses were combined into summary scores, where higher scores indicated better self-management. Cronbach's $\alpha$-coefficients for subscale and the total scale were $0.757-0.911$ and 0.914 , respectively. This accepted and specialized questionnaire has been used widely to evaluate hypertensive patients' self-management. ${ }^{30,31}$ Because the medication-management subscale was not statistically correlated with total self-management in our study, we substituted it for the MGL score.

\section{Data collection and management}

Data were collected from July to September in 2017. All interviewers, examiners, and supervisors were graduate students at the School of Public Health of Sun Yat-sen University and received professional training. In total, 289 records were included in the original database. After excluding duplicated (ten) and missing (eleven) essential records, 268 individuals remained in the study. The response rate was $92.7 \%$. Logical and median imputations were applied to replace missing values. The database was established using EpiData version 3.1 (EpiData Association, Odense, Denmark), and all questionnaires were coded and double entered by two independent professional data-entry staff.

\section{Statistical analysis}

First, descriptive analysis was performed for demographicdisease and measured variables. We applied skewness and kurtosis to evaluate variable normality. For the skewness index, absolute values $>3$ are extreme. For the kurtosis index, absolute values $>10$ suggest a problem and $>20$ are extreme. ${ }^{32}$ The skewness of the study variables was $0.11-1.68$, and kurtosis statistics ranged from 0.13 to 4.12 (Table 5). Therefore, no preprocessing was needed to improve the distributional properties. To facilitate comparison of scores, standard scores were calculated as such:

$$
\text { Standard score }=\frac{\text { Actual score }}{\text { Possible score }} \times 100
$$

and divided into low $(<60)$, moderate $(60-80)$, and high $(>80)$ levels. ${ }^{29}$ Secondly, Pearson's correlation coefficients were used to identify relationships among the measured variables. The $\chi^{2}$ test was applied to confirm the association between level of self-management and hypertensioncontrol status.

Lastly, the SEM was employed to verify relationships between self-management and its influencing factors. A twostep analytic approach was employed by first estimating measurement models using confirmatory factor analysis and then testing a structural model. $\mathrm{Hu}$ et al found that the generalized least squares estimator would be better if the sample size were $<500,{ }^{33}$ and it has more robust estimation, even when data violated the multivariate normality assumption. ${ }^{22}$ As such, the generalized least squares estimator was chosen to assess the analysis. Three types of model-fit indices were used to evaluate whether the data fit the theoretical model: 1$)$ absolute fit $-\chi^{2}(P>0.05), \chi^{2} / d f$ $(<2)$, goodness-of-fit index (GFI; $>0.90) /$ adjusted GFI 
(AGFI; >0.90), and root-mean-square error of approximation (RMSEA; <0.05); 2) relative fit - comparative fit $(\mathrm{CFI} ;>0.90)$ and Tucker-Lewis index (TLI >0.90); and 3) parsimony fit - Akaike information criterion (AIC), consistent AIC (CAIC), and parsimony-adjusted normedfit index (PNFI; >0.50). Data were analyzed using SPSS version 20.0 and Amos version 24.0 software.

\section{Results}

\section{Demographic-disease characteristics}

The study recruited 268 community-dwelling hypertensive patients with a mean age of $61.34 \pm 5.97$ years and mean disease course of $9.16 \pm 7.89$ years. The majority of participants were female (66.4\%), married/cohabitating (85.4\%), retired (86.2\%), with high school education (73.2\%), financially secure $(44.8 \%)$, with urban employed basic medical insurance $(81.0 \%)$. The majority of participants were at stage 1 (90.7\%) and with high CVD risk (55.2\%). Specific demographic data are presented in Table 2.

Table 2 Demographics and disease characteristics of participants $(n=268)$

\begin{tabular}{|c|c|c|}
\hline & $\mathbf{n}$ & $\%$ \\
\hline \multicolumn{3}{|l|}{ Sex } \\
\hline Male & 90 & 33.6 \\
\hline Female & 178 & 66.4 \\
\hline \multicolumn{3}{|l|}{ Age-group, years } \\
\hline $45-49$ & 10 & 3.7 \\
\hline $50-54$ & 30 & 11.2 \\
\hline $55-59$ & 57 & 21.3 \\
\hline $60-54$ & 75 & 28.0 \\
\hline $65-70$ & 96 & 35.8 \\
\hline \multicolumn{3}{|l|}{ Education } \\
\hline Primary school or below & 26 & 9.7 \\
\hline High school & 196 & 73.1 \\
\hline College or above & 46 & 17.2 \\
\hline \multicolumn{3}{|l|}{ Marital status } \\
\hline Single & 4 & 1.5 \\
\hline Married/cohabitating & 229 & 85.4 \\
\hline Divorced/widowed & 35 & 13.1 \\
\hline \multicolumn{3}{|l|}{ Employment } \\
\hline Retired & 231 & 86.2 \\
\hline Employed & 35 & 13.1 \\
\hline Unemployed & 2 & 0.7 \\
\hline \multicolumn{3}{|l|}{ Per capita disposable income, CN¥ } \\
\hline$\leq \mathrm{I}, 200$ (very poor) & 6 & 2.2 \\
\hline $\mathrm{I}, 20 \mathrm{I}-2,000$ (poor) & 21 & 7.8 \\
\hline $2,00 \mathrm{I}-3,000$ (average) & 80 & 29.9 \\
\hline $3,00 \mathrm{I}-4,500$ (good) & 120 & 44.8 \\
\hline$>4,500$ (very good) & 41 & 15.3 \\
\hline \multicolumn{3}{|l|}{ Medical insurance } \\
\hline Urban employed basic medical insurance & 217 & 81.0 \\
\hline Urban resident basic medical insurance & 37 & 13.8 \\
\hline
\end{tabular}

Table 2 (Continued)

\begin{tabular}{l|l|l}
\hline & $\mathbf{n}$ & $\%$ \\
\hline $\begin{array}{l}\text { Other medical insurance } \\
\text { Self-financed }\end{array}$ & 10 & 3.7 \\
BMI, kg/m ${ }^{2}$ & 4 & 1.5 \\
$<18.5$ & 10 & \\
I8.5-23.9 & 121 & 3.7 \\
$24-27.9$ & 95 & 45.1 \\
$\geq 28$ & 42 & 35.4 \\
Disease course, years & & 15.7 \\
$\leq$ I & 25 & \\
I.I-5 & 85 & 9.3 \\
$5 . I-10$ & 78 & 31.7 \\
I0.I-50 & 80 & 29.1 \\
Clinical complications & & 29.9 \\
Yes & 115 & \\
No & 153 & 42.9 \\
Family history of hypertension & & 57.1 \\
Yes & 202 & 75.4 \\
No & 66 & 24.6 \\
Hypertension & & \\
Stage I & 243 & 90.7 \\
Stage 2 & 18 & 6.7 \\
Stage 3 & 7 & 2.6 \\
CVD risk & & \\
Low & 14 & 5.2 \\
Moderate & 106 & 39.6 \\
High & 148 & 55.2 \\
Control & & \\
Controlled & 170 & 63.4 \\
Uncontrolled & 98 & 36.6 \\
\hline Abbrevition & \\
\hline & & \\
\hline
\end{tabular}

Abbreviations: BMI, body-mass index; CVD, cardiovascular disease.

\section{Disease knowledge, social support, self-efficacy, and self-management}

The majority of participants had low hypertension knowledge (64.6\%), high self-efficacy (80.2\%), and low social support (57.8\%; Table 3).

Table 3 Levels of disease knowledge, social support, and selfefficacy $(n=268)$

\begin{tabular}{|c|c|c|}
\hline & $\mathbf{n}$ & Mean \pm SD $/ \%$ \\
\hline Disease knowledge & 268 & $13.76 \pm 5.87$ \\
\hline Low $(\leq 16)$ & 173 & 64.6 \\
\hline Moderate (17-22) & 75 & 28.0 \\
\hline High (23-28) & 20 & 7.5 \\
\hline Social support & 268 & $37.09 \pm 6.61$ \\
\hline Low $(\leq 38)$ & 155 & 57.8 \\
\hline Moderate (39-5I) & 108 & 40.3 \\
\hline High (52-64) & 5 & 1.9 \\
\hline Self-efficacy & 268 & $66.15 \pm 6.63$ \\
\hline Low $(\leq 45)$ & 2 & 0.7 \\
\hline Moderate (46-60) & 51 & 19.0 \\
\hline High (6I-75) & 215 & 80.2 \\
\hline
\end{tabular}


Table 4 Self-management levels of participants $(n=268)$

\begin{tabular}{l|l|l|l|l|l|l|l}
\hline & Mean \pm SD & \multicolumn{2}{l}{ Low } & \multicolumn{2}{l|}{ Moderate } & \multicolumn{2}{l}{ High } \\
\cline { 3 - 8 } & & $\mathbf{n}$ & $\%$ & $\mathbf{n}$ & $\%$ & $\mathbf{n}$ & $\%$ \\
\hline Medication adherence & $70.80 \pm 34.67$ & 108 & 40.3 & 25 & 9.3 & 135 & 50.4 \\
Condition monitoring & $79.38 \pm 18.40$ & 56 & 20.9 & 81 & 30.2 & 131 & 48.9 \\
Diet management & $87.28 \pm 11.01$ & 9 & 3.4 & 54 & 20.1 & 205 & 76.5 \\
Sport management & $84.30 \pm 21.88$ & 53 & 19.8 & 49 & 18.3 & 166 & 61.9 \\
Work management & $83.63 \pm 18.47$ & 48 & 17.9 & 46 & 17.2 & 174 & 64.9 \\
Emotion management & $87.36 \pm 16.11$ & 23 & 8.6 & 53 & 19.8 & 192 & 71.6 \\
Total & $86.01 \pm 9.00$ & 1 & 0.4 & 68 & 25.4 & 199 & 74.3 \\
\hline
\end{tabular}

The total standard score for hypertension self-management was 86.01 \pm 9.00 (Table 4), showing a high self-management level in our study population. The six dimensions in descending order were emotion management, diet management, sport management, work management, condition monitoring, and medication adherence. Moreover, participants with a high level of self-management were more likely to have their hypertension controlled $\left(\chi^{2}=9.758, P=0.002\right)$.

\section{Correlation matrix of measured variables}

Correlation analysis supported the relationships among the study variables in the proposed model (Table 5). Disease knowledge and social support were correlated with each other, and both positively associated with hypertension selfefficacy. Also, self-efficacy was positively related to each self-management behavior.

\section{Testing the proposed model}

The first step was confirmatory factor analysis to estimate the latent variable hypertension self-management. If the medication-adherence dimension was designated the original scale, none of the factor loadings between the latent variable and its indicators were statistically significant, even after modification $(P=0.882-0.883)$. We then chose the MGL score as the medication-adherence dimension, due to the similar content. This model gave significant associations between each self-management behavior and the latent variable $(P=0.002-0.015)$, as well as good fit with the data $\left(\chi_{7,268}^{2}=7.690, \mathrm{GFI}=0.990, \mathrm{RMSEA}=0.019, \mathrm{CFI}=0.989\right.$, $\mathrm{TLI}=0.977)$. Composite reliability $(\mathrm{CR})$ was used to measure internal consistency for the latent variable. According to Fornell and Larcker, ${ }^{34} \mathrm{CR}$ should be $>0.6$. The CR coefficient in our study was 0.636 , which confirmed the factor structure in the model. Next, a structural model was established based on the self-efficacy theory and literature review. This model, shown in Figure 1, resulted in good fit with the data $\left(\chi_{7,268}^{2}=58.324, \chi^{2} / d f=1.241, P=0.124\right.$, $\mathrm{GFI}=0.964, \mathrm{AGFI}=0.940, \mathrm{RMSEA}=0.030, \mathrm{CFI}=0.932$, $\mathrm{TLI}=0.905, \mathrm{PNFI}=0.534$ ).

\section{Hypothesis I: Self-efficacy is positively related to self-management}

The first hypothesis was supported by the structural model. Self-efficacy was positively and significantly associated with

Table 5 Correlations among observed variables

\begin{tabular}{|c|c|c|c|c|c|c|c|c|c|c|c|}
\hline & I & 2 & 3 & 4 & 5 & 6 & 7 & 8 & 9 & 10 & I I \\
\hline I. Age & & & & & & & & & & & \\
\hline 2. Disease course & $0.28 * *$ & & & & & & & & & & \\
\hline 3. Disease knowledge & -0.02 & 0.08 & & & & & & & & & \\
\hline 4. Social support & $-0.19 * *$ & -0.10 & $0.24 * *$ & & & & & & & & \\
\hline 5. Self-efficacy & $0.18 * *$ & $0.15 *$ & $0.20 * *$ & $0.26 * *$ & & & & & & & \\
\hline 6. Medication adherence & $0.13 *$ & $0.13 *$ & 0.07 & 0.02 & $0.44 * *$ & & & & & & \\
\hline 7. Condition monitoring & 0.11 & 0.04 & $0.2 I^{* *}$ & 0.04 & $0.47 * *$ & $0.20 * *$ & & & & & \\
\hline 8. Diet management & $0.17 * *$ & 0.07 & $0.16 *$ & $0.24 * *$ & $0.59 * *$ & 0.10 & $0.33 * *$ & & & & \\
\hline 9. Sport management & $0.14 *$ & 0.05 & $0.12 *$ & 0.05 & $0.25 * *$ & 0.05 & $0.18 * *$ & $0.21 * *$ & & & \\
\hline I0. Work management & 0.08 & 0.04 & $0.17 * *$ & $0.17 * *$ & $0.38 * *$ & $0.38 * *$ & 0.03 & $0.43 * *$ & $0.34 * *$ & & \\
\hline II. Emotion management & 0.04 & 0.03 & 0.01 & 0.10 & $0.25 * *$ & 0.06 & $0.16 * *$ & $0.21 * *$ & $0.21 * *$ & $0.27 * *$ & \\
\hline Mean & 61.34 & 9.16 & 13.76 & 37.09 & 66.15 & 2.83 & 15.88 & 43.64 & 12.65 & 20.91 & 30.57 \\
\hline Scale range & $45-70$ & $5-50$ & $0-26$ & $17-56$ & $42-75$ & $0-4$ & $4-20$ & $20-50$ & $3-15$ & $7-25$ & $9-35$ \\
\hline SD & 5.97 & 7.89 & 5.87 & 6.61 & 6.63 & 1.39 & 3.68 & 5.50 & 3.28 & 4.62 & 5.64 \\
\hline Skewness & -0.54 & 1.68 & -0.15 & -0.11 & -0.90 & -0.83 & -0.77 & -1.27 & -1.36 & -0.98 & -1.59 \\
\hline Kurtosis & -0.46 & 4.12 & -0.64 & 0.22 & 0.59 & -0.56 & -0.13 & I.70 & 0.96 & -0.19 & 2.31 \\
\hline
\end{tabular}

Notes: $* p<0.05 ; * * p<0.01$. 


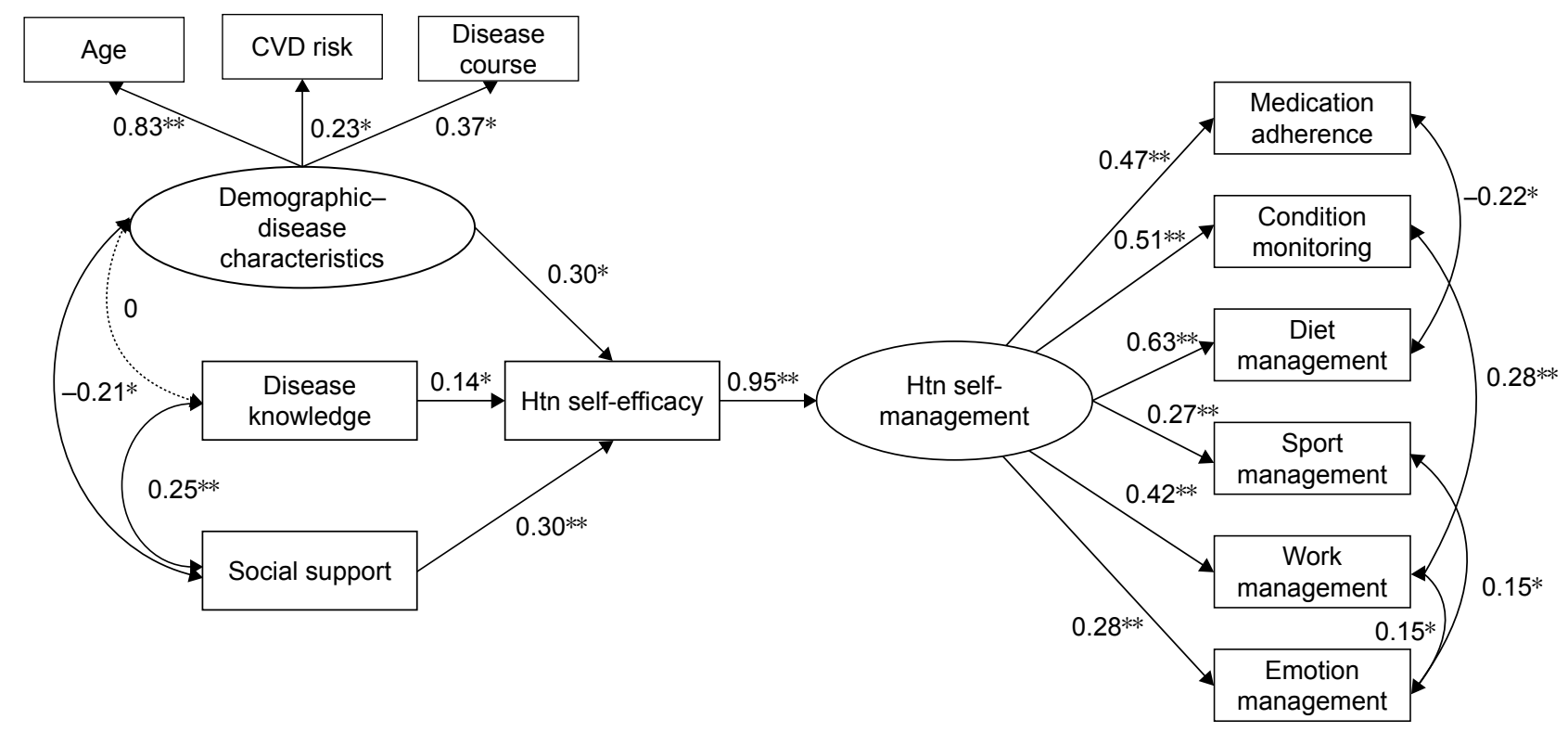

Figure I Structural equation model with standardized estimates.

Notes: $* P<0.05 ; * * P<0.001$. Solid lines, paths differing significantly from zero; dotted lines, paths not differing significantly from zero. Abbreviations: CVD, cardiovascular disease; $\mathrm{Htn}$, hypertension.

self-management $(\beta=0.954, P<0.001)$. Hypertension selfefficacy predicted $90.9 \%$ of self-management.

\section{Hypothesis 2: Patient disease knowledge and social support are positively related to self-management via self-efficacy}

The second hypothesis was proved. Disease knowledge ( $\beta=0.142, P=0.028)$ and social support $(\beta=0.292, P<0.001)$ had significant direct effects on self-efficacy and significant indirect effects on self-management ( $\beta=0.135$ and $\beta=0.279$, respectively).

\section{Hypothesis 3: Demographic-disease} characteristics are mediators in the model In this study, age, CVD risk, and disease course were significantly associated with self-efficacy and positively correlated with self-management. The total standard effects of age, CVD risk, and disease course on hypertension self-management were $0.237,0.067$, and 0.107 , respectively. Additionally, disease knowledge was positively correlated with social support $(\beta=0.245, P<0.001)$, suggesting that increased social support would improve patients' perception of disease. Several error terms were correlated after model modification, indicating they reflected a common latent trait.

\section{Discussion}

This study was designed to integrate factors associated with self-management among community-dwelling hypertensive patients in Guangzhou, China. The results supported the proposed hypotheses that self-efficacy was associated with self-management and that age, CVD risk, disease course, disease knowledge, and social support were related to self-management via self-efficacy. We also confirmed that higher levels of self-management were correlated with more hypertension control.

In contrast to traditional patient education, which focuses mainly on defining problems, self-management programs focus on developing problem-solving skills to help patients make decisions, take appropriate actions, and modify these actions in different circumstances ${ }^{35}$ and were proved to decrease systolic BP by $5 \mathrm{mmHg}$ and diastolic BP by $4.3 \mathrm{mmHg} .{ }^{36}$ The level of hypertension self-management in our study population was higher than other earlier studies in China, ${ }^{30,31}$ which may be explained by rapid economic growth, convenient access to information, and implementation of policies for chronic-disease management.

Medication adherence ranked the lowest among the six dimensions of self-management, which was similar to previous studies. ${ }^{31}$ The mean prevalence of nonadherence to antihypertensive treatments was $30 \%$ in an earlier study, ${ }^{37}$ while our study showed a higher rate of $49.6 \%$, indicating that participants might have had less awareness of disease hazards and underrated the importance of pharmaceutical treatment. Taking the high levels of total self-management into consideration, we suppose that patients, especially controlled ones, might have more willingness to seek nonpharmacological approaches, such as exercise and dietary practices, to avoid adverse events associated with antihypertensive medicaions. ${ }^{38}$ 
As such, knowledge about the adverse events of antihypertensive medications and the severity of nonadherence are needed urgently for hypertensive patients.

The effect of self-efficacy on self-management followed its expected direction, which has been found in diverse hypertensive groups, ${ }^{11,39}$ that higher level of confidence in patients' ability to develop management behaviors can significantly contribute to better self-management and hypertension control. Interventions targeting four ingredients of self-efficacy are effective. However, few studies have applied an SEM to combined analysis of all components in self-management or reveal relationships among internal components in any depth.

Through this study, we found that positive associations between disease knowledge or social support and selfmanagement were both via self-efficacy, ie, comprehensive understanding of disease gives patients a sense of confidence to self-manage hypertension and a supportive other provides hands-on help with verbal encouragement or indirect beneficial effects on motivation, coping, and psychological well-being, ${ }^{14}$ which increases self-efficacy and then develops self-management behavior. To achieve these ends, we should spare no effort in disease education, not only for patients but also involving the patient's supporters - friends, family members, general practitioners - to provide positive support and feedback.

In our study, older age, longer disease course, and severer CVD risk were additionally associated with better self-efficacy and self-management. This was consistent with several previous studies, ${ }^{31,39,40}$ where elderly retired individuals usually had abundant time to self-manage chronic conditions and patients with longer duration or related complications were more likely to receive regular care and better understand the importance of self-management. However, other studies have argued that younger patients are more open-minded and willing to change unhealthy behavior, contributing to a higher self-management level. ${ }^{18,30}$ Longitudinal and largescale studies are needed to clarify this question.

Compared with younger patients and those with milder hypertension, older patients with severer conditions have less social support and needed more care. They are left alone, with little support or self-management, as a result of being abandoned by deceased family members and friends or due to the heavy burden. ${ }^{41}$ Also, disease knowledge was positively associated with social support. To be specific, literate patients may seek more social support; reciprocally, patients with more social support may receive more disease knowledge from friends and family members, which is also supported by previous studies. ${ }^{14}$
To the best of our knowledge, the study is the first to integrate multiple factors associated with self-management using SEM among community-dwelling hypertensive patients in Guangzhou. The questionnaires we used have already been verified in Chinese populations. Furthermore, unlike other studies using simple hypertension stages, we applied CVD risk to embody fully the severity of disease with certain medical guidance.

\section{Limitations}

However, there are several limitations in this study. First, causal relationships cannot be revealed by a cross-sectional study, and relationships among the latent variables were assumed to be correlated and not causal. Second, selfreported social support, self-efficacy, and self-management may have been overestimated, due to selection and response biases. However, we informed all outpatients about our program, introduced detailed questionnaire-filling rules to participants, provided assistance while filling, and checked mistakes after filling, trying to reduce these biases as much as possible. Lastly, community-dwelling hypertensive patients in Guangzhou may be less representative when generalizing our findings to other populations.

The findings have several practical implications for medical professionals and individuals. Hypertensive patients that are young and with new-onset disease, low CVD risk, little disease knowledge or social support, and inferior self-efficacy are a vulnerable population to which medical professionals should pay more attention. Unlike socioeconomic determinants, which are less changeable, disease education and mutual-help groups are potential solutions. In addition to regular education, experts should focus on adverse disease outcomes and pharmaceutical treatment to eliminate patients' concerns about adverse events and improve medication adherence. Mutual-help groups should be organized regularly to deliver peer support and provide opportunities to share disease knowledge and vicarious experience, the two important components of self-efficacy. Internet and mobile health technology can be widely used, such as telemonitoring, which has been proved to be costeffective..$^{42}$ Meanwhile, patients should be aware that they are the principal caregivers in the long term to assess CVD risk routinely, interact with supporters, and maintain adherence to self-management instructions. Collaborative goal-setting, motivational interviewing, and financial incentives seem to be effective methods to arouse patients' enthusiasm to improve their self-efficacy and self-management. ${ }^{43}$ Further research is needed to implement and evaluate intervention 
studies aimed at community hypertension management, particularly focusing on vulnerable patients.

\section{Conclusion}

This study integrated factors associated with self-management among community-dwelling hypertensive patients using SEM. The level of self-management in our study population was high, but with a low level of medication adherence. Age, CVD risk, disease course, disease knowledge, and social support were indirectly and positively correlated with self-management via self-efficacy. Medical professionals and patients should work together to enhance self-efficacy by gaining disease knowledge and social support, such as disease-education programs and mutual-help groups. Further research is needed to implement and evaluate related interventions to improve patient self-management and health status.

\section{Acknowledgment}

We thank the community physicians who supported our study and residents for their enthusiastic participation.

\section{Author contributions}

AHL, WWD, TL, QYS, and MHY were responsible for conceptualization, WWD for methodology, software, validation, and formal analysis, WWD and TL for investigation, QYS and MHY for resources, WWD and TL for data management, WWD for original draft preparation, WWD, TL, AHL, QYS, and MHY for writing, review, and editing, WWD for visualization, AHL and QYS for supervision, WWD, TL, and MHY for project administration, and WWD and AHL for funding acquisition. All authors contributed to data analysis, drafting and revising the article, gave final approval of the version to be published, and agree to be accountable for all aspects of the work.

\section{Disclosure}

The authors report no conflicts of interest in this work.

\section{References}

1. WHO. Global status report on noncommunicable disease; 2014. Available from: http://www.who.int/nmh/publications/ncd-status-report-2014/en. Accessed October 04, 2018.

2. GBD 2015 Risk Factors Collaborators. Global, regional, and national comparative risk assessment of 79 behavioural, environmental and occupational, and metabolic risks or clusters of risks, 1990-2015: a systematic analysis for the Global Burden of Disease Study 2015. Lancet. 2016; 388(10053):1659-1724.

3. Wang Z, Chen Z, Zhang L, et al. Status of Hypertension in China: Results From the China Hypertension Survey, 2012-2015. Circulation. 2018;137(22):2344-2356.

4. Forouzanfar MH, Liu P, Roth GA, et al. Global Burden of Hypertension and Systolic Blood Pressure of at Least 110 to $115 \mathrm{~mm} \mathrm{Hg}, 1990-2015$. JAMA. 2017;317(2):165-182.
5. Mills KT, Bundy JD, Kelly TN, et al. Global Disparities of Hypertension Prevalence and Control: A Systematic Analysis of Population-Based Studies From 90 Countries. Circulation. 2016;134(6):441-450.

6. Ellen N, Martin M. Caring for People with Chronic Conditions: A Health System Perspective. England: Open University Press; 2008.

7. Barlow J, Wright C, Sheasby J, Turner A, Hainsworth J. Self-management approaches for people with chronic conditions: a review. Patient Educ Couns. 2002;48(2):177-187.

8. Lorig KR, Holman H. Self-Management Education: history, definition, outcomes, and mechanisms. Ann Behav Med. 2003;26(1):1-7.

9. Albert B. Self-efficacy: Toward a unifying theory of behavioral change. Adv Behav Res Ther. 1978;1(4):139-161.

10. Lorig KR, Sobel DS, Stewart AL, et al. Evidence suggesting that a chronic disease self-management program can improve health status while reducing hospitalization: a randomized trial. Med Care. 1999; 37(1):5-14.

11. Warren-Findlow J, Seymour RB, Brunner Huber LR, Huber LRB. The association between self-efficacy and hypertension self-care activities among African American adults. J Community Health. 2012;37(1): $15-24$.

12. Lu CH, Tang ST, Lei YX, et al. Community-based interventions in hypertensive patients: a comparison of three health education strategies. BMC Public Health. 2015;15:33.

13. Thoits PA, Stress TPA. Stress, coping, and social support processes: where are we? What next? J Health Soc Behav. 1995;35:53-79.

14. Gallant MP. The influence of social support on chronic illness selfmanagement: a review and directions for research. Health Educ Behav. 2003;30(2):170-195.

15. Osborn CY, Paasche-Orlow MK, Bailey SC, Wolf MS. The mechanisms linking health literacy to behavior and health status. Am J Health Behav. 2011;35(1):118-128.

16. Wortman CB, Conwat TL. The role of social support in adaptation and recovery from physical illness. In: Cohen S, Syme SL, editors. Social Support and Health; San Diego, CA: Academic Press; 1985:281-302.

17. Perez A. Self-management of hypertension in Hispanic adults. Clin Nurs Res. 2011;20(4):347-365.

18. Krousel-Wood MA, Muntner P, Islam T, Morisky DE, Webber LS. Barriers to and determinants of medication adherence in hypertension management: perspective of the cohort study of medication adherence among older adults. Med Clin North Am. 2009;93(3):753-769.

19. Dong X, Rao J, Ye Y, et al. Trends and Associated Factors of Hypertension among Residents Aged $\geq 15$ Years in Guangzhou, China, 2004-2013. Iran J Public Health. 2018;47(2):198-208.

20. Wu X, Pan B, Chen X, et al. Useful information for hypertension management reform in community health care: prevalence, awareness, treatment and control among Guangzhou adults. Clin Exp Hypertens. 2014;36(4):227-235.

21. Williams LJ, Vandenberg RJ, Edwards JR. Structural Equation Modeling in Management Research: A Guide for Improved Analysis. Acad Manag Ann. 2009;3(1):543-604.

22. Wu M. Structural Equation Modeling: Operation and Application of AMOS. China: Chongqing University Press; 2009.

23. Liu L. [2010 Chinese guidelines for the management of hypertension]. Chin J Cardiol. 2011;39(7):579-615. Chinese.

24. Wu Z, Huo Y, Wang W, Zhao L, Zhu D. [Guidelines for Patient Education of Hypertension]. Chin J Hypertension. 2013;12(10): 1123-1149. Chinese.

25. Lan G, Yuan Z, Cook A, et al. The relationships among social support and quality of life in persons living with HIV/AIDS in Jiangxi and Zhejiang provinces, China. AIDS Care. 2015;27(8):946-953.

26. Chen J. Analysis and Intervention of Knowledge, Belief, Behavior in Elderly Patients with Primary Hypertension in Haizhu District of Guangzhou. China: Southern Medical University; 2011. 
27. Morisky DE, Green LW, Levine DM. Concurrent and predictive validity of a self-reported measure of medication adherence. Med Care. 1986; 24(1):67-74.

28. Xu W, Wang Q, Liang W. Reliability and validity of Morisky questionnaire in measurement of the compliance with hypertensive medications. Chin J Prev Contr Chron Non-Commun Dis. 2007;15(5):424-426.

29. Zhao Q, Liu X. Reliability and validity of the hypertension patients self-management behavior rating scale. Chin Nurs Manag. 2012;12(11):26-31.

30. Cheng X. The Predictors of Self-Management Behavior in Patients with Hypertension Based on Health Ecological Model. China: Shandong University; 2014.

31. Liu X, Zhao Q, Li J. Self-management level and its influencing factors among patients with hypertension. Nurs J Chin PLA. 2013;30(20):5-8.

32. Weston R, Gore PA. A brief guide to structural equation modeling. Couns Psychol. 2006;34(5):719-751.

33. Hu LT, Bentler PM, Kano Y. Can test statistics in covariance structure analysis be trusted? Psychol Bull. 1992;112(2):351-362.

34. Fornell C, Larcker DF. Evaluating Structural Equation Models with Unobservable Variables and Measurement Error. J Market Res. 1981; 18(1):39-50.

35. Bodenheimer T, Lorig K, Holman H, Grumbach K. Patient selfmanagement of chronic disease in primary care. JAMA. 2002;288(19): 2469-2475.
36. Chodosh J, Morton SC, Mojica W, et al. Meta-analysis: chronic disease self-management programs for older adults. Ann Intern Med. 2005; 143(6):427-438.

37. Cramer JA, Benedict A, Muszbek N, Keskinaslan A, Khan ZM. The significance of compliance and persistence in the treatment of diabetes, hypertension and dyslipidaemia: a review. Int J Clin Pract. 2008; 62(1):76-87.

38. Hyman DJ, Pavlik V. Medication adherence and resistant hypertension. J Hum Hypertens. 2015;29(4):213-218.

39. Lee JE, Han HR, Song H, et al. Correlates of self-care behaviors for managing hypertension among Korean Americans: a questionnaire survey. Int J Nurs Stud. 2010;47(4):411-417.

40. Zhang Y, Li X, Mao L, et al. Factors affecting medication adherence in community-managed patients with hypertension based on the principal component analysis: evidence from Xinjiang, China. Patient Prefer Adherence. 2018;12:803-812.

41. House JS, Umberson D, Landis KR. Structures and Processes of Social Support. Annu Rev Sociol. 1988;14(1):293-318.

42. Chandak A, Joshi A. Self-management of hypertension using technology enabled interventions in primary care settings. Technol Health Care. 2015;23(2):119-128.

43. Bosworth HB, Powers BJ, Oddone EZ. Patient self-management support: novel strategies in hypertension and heart disease. Cardiol Clin. 2010;28(4):655-663.
Patient Preference and Adherence

\section{Publish your work in this journal}

Patient Preference and Adherence is an international, peer-reviewed, open access journal that focuses on the growing importance of patient preference and adherence throughout the therapeutic continuum. Patient satisfaction, acceptability, quality of life, compliance, persistence and their role in developing new therapeutic modalities and compounds to optimize

\section{Dovepress}

clinical outcomes for existing disease states are major areas of interest for the journal. This journal has been accepted for indexing on PubMed Central. The manuscript management system is completely online and includes a very quick and fair peer-review system, which is all easy to use. Visit http://www. dovepress.com/testimonials.php to read real quotes from published authors. 